\title{
Principios del proceso civil
}

\author{
IGNACIO SIERRA GIL DE LA CUESTA \\ Vocal del Consejo General del Poder Judicial
}

El proceso civil es el cauce por el que discurre una contienda judicial, en la que se dilucidan pretensiones que se enclavan en el área del derecho privado, y principalmente las relativas al derecho civil y mercantil.

Ahora bien, esa naturaleza privatista hace que los principios específicos del proceso civil, reúnan unas características específicas, pero en ningún caso ajenas o contrarias a los principios generales o constitucionales del proceso.

Sin embargo, hay que decir como prolegómeno obligado que, los principios del proceso civil son todas las orientaciones básicas de la ordenación procesal civil, y para una mejor comprensión de los mismos, hay que examinarlos desde una doble vertiente: la una, desde un punto de vista dogmático, y la otra, desde un punto de vista de política jurídica. En la primera vertiente, mediante un problema de abstracción. se obtienen los principios básicos de un sistema procesal en general y civil en particular; y en la segunda antedicha vertiente, se valoran estos principios procesales en relación con el fin de la institución, atendidas las necesidades socio-políticas de una época concreta.

Como compendio de las mencionadas vertientes, hay que decir, y con ello simplificar totalmente la cuestión, que las mismas convergen en la 
"Kelseniana" - norma hipotética fundamental-, o sea, dicho lisa y llanamente en la Constitución.

De lo afirmado anteriormente se deduce claramente que es dentro de la norma constitucional de donde hay que inferir de una manera general los principios del proceso, y en particular los del proceso civil.

Ln dato que puede constituir un axioma dentro del Derecho Privado. es que, en la generalidad de los regímenes políticos modernos de los siglos XIX y XX se han promulgado numerosas constituciones y sin embargo las instituciones fundamentales del Derecho Civil -propiedad, obligaciones, familia, sucesiones - han permanecido inalterables en las numerosas vicisitudes constitucionales acaecidas.

Las fuentes concretas reguladoras del proceso civil se encuentran en la Constitución española de 1978, en particular es en el paradigmático art. 24 que proclama y regula el derecho a la tutela judicial efectiva, con todas las consecuencias que la misma significa y que desarrollaremos más tarde, al estudiar los principios del proceso civil en particular.

Ahora bien, del núcleo de la tutela judicial efectiva se desprenden una serie de principios que rigen el proceso civil. En la presente disertación se dedicará una especial atención a los principios de audiencia, al de contradicción y al principio de defensa. Sin embargo no se puede hablar de los principios del proceso civil sin mencionar, aunque sea de una manera muy somera los siguientes:

a) La oralidad. Dicho principio aparece recogido en el art. 120 de la Constitución española, cuando en su apartado $2^{\circ}$, establece que el procedimiento será predominantemente oral, y que significa que el conjunto de los actos procesales civiles deben ser mayoritariamente orales, con independencia de que sean actos del Juez o actos de las partes.

Ahora bien, este principio de oralidad, no es un mero capricho de estilo, sino que reviste una enorme importancia, ya que a través del mismo se impide que se realicen actos procesales fuera de la prevención y control directo del Juez; y por lo tanto se establece el método de trabajo de la inmediación, que significa un valor procesal en sí mismo y que es imprescindible para que el órgano judicial perciba directamente los actos procesales, y con 
ello tenga los datos precisos para resolver una concreta contienda judicial.

Pues como muy bien dice el profesor Cortés Domínguez, el principio de oralidad hace imposible que se realicen actos procesales civiles fuera de la presencia judicial. Todo lo cual lleva a la necesidad de la inmediación judicial por parte del Juez, y que sea la que fuere la valoración que se quiera dar a la misma, se tiene que dejar fuera las apreciaciones más o menos sociológicas sobre si es más o menos eficaz, o si es más o menos posible o imprescindible que el órgano reciba directamente los autos procedentes.

En resumen, que la inmediación es una consecuencia constitucional del principio de inmediación.

b) La publicidad. Este principio se explicita en el art. 20-1 ${ }^{\circ}$ de la Constitución española, cuando en él se dice que las actuaciones judiciales serán públicas con las excepciones que prevean las leyes de procedimiento; dicho principio es importante no sólo para plasmar el brocardo de "luz y taquígrafos" de repercusión externa social sino para obligar a que en el proceso civil exista un sistema apropiado de comunicación y notificación internas de las actuaciones judiciales.

La necesidad de la publicidad está fuera de dudas, ya que la desaparición del proceso inquisitivo y las exigencias de un proceso moderno se produce como dice la sentencia del T.C. de 10-VI-87, porque la vigencia de la publicidad implica un control social sobre el desarrollo de la actividad judicial.

c) La motivación de las sentencias. La Constitución Española de 1978 ha pretendido. y logrado, dar el carácter de principio constitucional a varias notas de carácter procesal relativas al cometido de Juzgados y Tribunales, en el ejercicio de su potestad jurisdiccional, con la finalidad de destacar su independencia y dar base suficiente a la tutela judicial efectiva, que otorgan.

Entre estas notas hay que destacar la de la motivación de las sentencias, recogida, junto a la de publicidad de las mismas en audiencia pública, en el artículo 120.3 de la Constitución Española.

Este precepto ha elevado a rango constitucional el principio procesal de la motivación de las sentencias. Y es por ello que dicho principio aparece, a su vez, como un deber u obligación de todos los órganos judiciales y un derecho constitucional, exigible por los ciudadanos. 
Ahora bien, ¿Qué se entiende por motivación de la sentencia? Desde un punto de vista amplio, supone la motivación, la obligación de todo Tribunal de Justicia de exponer las razones y argumentos que llevan o conducen al fallo judicial, los antecedentes de hecho y los fundamentos de derecho que lo sustentan.

Además este derecho y deber de motivación de la sentencia, aparte de cumplir un formalismo normativo, fundamenta y apoya el principio de legalidad; y sobre todo facilita a los interesados los datos, explicaciones y razonamientos necesarios para que el ciudadano pueda saber el porqué de su pretensión, y en todo caso posibilitando un recurso o un remedio procesal. Siempre que dicha motivación sea lo suficientemente clara y concisa, para que sea comprensible, no sólo al técnico jurídico, sino también al ciudadano en general. $\mathrm{O}$ sea, que imitando a Ortega y Gasset hagamos de la claridad la cortesía del Tribunal, como él la exigía al filósofo, al que pedía que nunca se interpusiera entre la teoría y la curiosidad de los profanos, el dragón tremebundo de su terminología hermética.

Entrando ya en materias más concretas, hay que buscar los fundamentos que llevan a la necesidad de motivar las resoluciones judiciales denominadas sentencias, entre ellos están:

$1^{\circ}$. Si la norma opera sobre la realidad social, al aplicarla al caso concreto, hay que hacerlo de manera adecuada, para lo que es necesario precisar su contenido, consecuencias y alcance, lo que adentrado en el área jurisdiccional es lo que hace que la resolución definitiva sea motivada.

$2^{\prime \prime}$. La labor del Juez al juzgar ha de tender ineludiblemente a garantizar efectivamente el imperio de la Ley, y dicho imperio en cada caso concreto ha de ser explicado, y esa explicación pasa inexorablemente por una argumentación o motivación, que justifique que en dicho caso concreto ha existido una perpetua adecuación de lo jurídico al orden real o de la praxis.

$3^{\circ}$. Desde un punto de vista estadístico, indica que los Jueces españoles, en su mayoría, estiman que lo que predetermina en su ánimo la sentencia a dictar en cada caso concreto proviene, de la Ley escrita, de la percepción de lo justo en cada caso concreto, del sentido común y de la jurisprudencia del Tribunal supremo: por lo que en todo caso esas pre- 
determinaciones tienen que ser explicadas al justiciable, motivándolas.

$4^{\circ}$. Asimismo, la motivación de la sentencia es un dato indicador del grado de formación y conocimiento del Juez al dictarla. Pues la motivación de la sentencia será siempre un reflejo fidedigno de un conocimiento suficiente del Derecho, así como de otras materias del área del humanismo, que servirán para calibrar el nivel cultural e intelectual del Juez sentenciador. La motivación de las sentencias tiene carácter, desde un punto de vista constitucional, de derecho fundamental del ciudadano, y así lo establece el artículo 24.1 de la Constitución Española, que consagra el derecho a una resolución fundada en Derecho (con mayúscula), lo que corrobora el ya mencionado artículo 120.3 de dicho Cuerpo Legal; todo ello sirve para elevar dicha motivación a rango constitucional, lo que antes en un simple imperativo legal (Sentencias del Tribunal Constitucional de 11-VII-83, 17-II-85, 27-VI-86, 13-X-86 y 10-II-87, entre otras).

Asimismo, el Tribunal Supremo ha dicho que las sentencias deben ser motivadas, expresando las razones de hecho y de derecho que las fundamentan, por exigencia de la Constitución y de la legislación procesal ordinaria, aunque a ello no se opone la parquedad o brevedad de los razonamientos ( $\mathrm{S}$. de la Sala Primera del Tribunal supremo de 10-IV-84). También la sentencia de la Sala Segunda de dicho Tribunal de 12-V-86 establece que el juzgador tiene que detallar las líneas generales del razonamiento que le llevan al fallo.

Ahora bien, la motivación siempre ha de ir acompañada de una técnica gramatical correcta, con el mejor estilo literario posible, huyendo siempre del barroquismo en la redacción, el fárrago, la dispersión, el mimetismo, el lenguaje confuso o equívoco, reiterativo o superfluo, lo que no concuerda con la regla ideal de una buena motivación en la sentencia.

Relacionado con la motivación de la sentencia, hay que resaltar las formalidades que la misma requiere, y así se conecta en el artículo 248.3 de la Ley Orgánica del Poder Judicial, que dice: "se formularán expresando, tras un encabezamiento, en párrafos separados y numerados, los antecedentes de hecho, hechos probados, en su caso, los fundamentos de Derecho y, por último, el fallo" . Este artículo tenía sus precedentes en el área civil, en el artículo 372 de la Ley de Enjuiciamiento Civil. 
Estudio especial merece este apartado de los "hechos probados", el cual debe contener exposición separada, precisa y completa de lo que el Juez ha constatado en cada causa, relativo a la cronología, desarrollo, detalle en cuanto pueda ser relevante y diferenciación de los datos útiles.

Pero es en el área penal, a pesar de la autorización del artículo 741 de la Ley de Enjuiciamiento Criminal que autoriza a la apreciación en conciencia de las pruebas practicadas, las nuevas exigencias derivadas del derecho a la presunción de inocencia que consagra el artículo 24.2 de la Constitución Española, en relación con la consiguiente necesidad de una mínima actividad probatoria producida con las debidas garantías procesales, que de alguna forma pueden entenderse de cargo y permitan deducir la culpabilidad del acusado; todo ello según abundantísima y pacífica doctrina jurisprudencial de la Sala Segunda del Tribunal Supremo; habiéndose visto potenciado lo anterior por lo dispuesto en el artículo 5.4 de la Ley Orgánica del Poder Judicial.

Pasando ya al tema de los Fundamentos de Derecho es el campo en donde propiamente surge con más fuerza el deber de la motivación. Ya que el Juez, en párrafos separados y numerados, explica los puntos de derecho fijados por él, dando las razones legales que se estimen procedentes para el fallo que haya de dictarse, citando las normas del Ordenamiento Jurídico y la Jurisprudencia que fueren aplicables para resolver el caso objeto del debate.

En resumen y como colofón, que la motivación de la sentencia penal es una exigencia constitucional; que es un deber del juzgador, que demuestra así sus conocimientos humanísticos y jurídicos, que es un derecho del ciudadano, que inquiere los motivos de una decisión que le afecta ya directa e indirectamente. Y por último que dicha motivación de la sentencia penal es una prueba más, en el complejo engranaje que configura un Estado social y democrático de Derecho, como es España a tenor del artículo 1.1 de la Constitución. 
Dicho principio supone lisa y llanamente el derecho que tiene toda persona a ser oído en el proceso en el cual sea parte.

El "sustratum" de dicho principio se encuentra en el derecho a la tutela judicial efectiva que proclama el art. 24-1 de la Constitución Española.

Este principio está insito de tal manera en el proceso civil, que sin él no puede entenderse la existencia de una justa contienda procesal, y se puede desarrollar con el aforismo de "auditur in altera pars", significando dicho principio como el dato de dar a cada parte procesal la facultad de intervenir en todas las fases del proceso civil desde el momento de su inicio - normalmente a través de la demanda - hasta el momento del agotamiento del mismo en su fase de ejecución.

Ahora bien, este principio de audiencia debe estar protegido y garantizado por los órganos judiciales, a través de los oportunos actos de comunicación especificados en las leyes procesales.

De todo lo anterior se desprende que la vulneración del principio de audiencia, produce una indefensión tal, en la parte procesal, que ataca de raíz el derecho constitucional de la tutela judicial efectiva, y para que ello ocurra será preciso que concurran los siguientes eventos:

a) Que por defecto grave en el acto de comunicación, ya sea un emplazamiento, una citación o una notificación se prive a una parte de la intervención en el proceso.

b) Que la parte no haya provocado con su postura, expresa o tácitamente, lo anteriormente mencionado, y además que no se hayan subsanado posteriormente los defectos en cuestión, por una actuación posterior de cualquiera de las partes.

El principio de audiencia aparece recogido en el derecho positivo español en varios preceptos de la Ley de Enjuiciamiento Givil, como por ejemplo los arts. 527 y 528 que permiten un segundo llamamiento al demandado que no fue emplazado personalmente, el art. 766 que permite intervenir en cualquier fase del proceso, así como el art. 1.692-3 que motiva el recurso de casación cuando se infringe el principio de audiencia. 
El paradigma de lo anterior se puede encontrar en el art. 238-3 de la Ley Orgánica del Poder Judicial, que proclama la nulidad de pleno derecho de los actos judiciales en los supuestos de violación del principio de audiencia, cuando produzcan indefensión.

Por otra parte, nuestro Tribunal Constitucional ha reconocido como "obiter dicta" este principio procesal civil de audiencia, en concreto en las sentencias 58-1.988 -el demandado ha de ser citado en forma: 83-1.983 - derecho a la última palabra en la fase de alegaciones.

Asimismo este principio ha sido proclamado por el Tribunal Europeo de Derechos Humanos, al proclamar en el caso Ozturk, el derecho al conocimiento previo de la pretensión y de los hechos que la motivan.

\section{EL PRINCIPIO PROGESAL CIVIL DE CONTRADICCIÓN}

Es este un principio procesal civil inherente a la estructura del proceso; de tal manera que si el mismo falta: se podrá hablar de cualquier fórmula autocompositiva, pero nunca de proceso.

En ningún caso se podrá hablar de un proceso actual o moderno, si no existen dos tesis contrapuestas, a través del choque entre la pretensión y su antitético razonamiento, y así lo proclama Calamandrei.

Centrando la cuestión, hay que decir que frente a la pretensión procesal surge normalmente, en todo proceso civil, la oposición del sujeto pasivo de aquella. La oposición a la pretensión se da en un proceso cuando la parte frente a quien la pretensión se dirige, lejos de aquietarse ante ella y de reconocerla, expresa o tácitamente, la combate.

Así la doctrina procesalista española moderna, afirma que lo consustancial en todo proceso, no es simplemente la existencia de dos partes, sino la existencia de dos posiciones contrapuestas, la del actor y la del demandado.

El principio procesal civil de contradicción, aparece proclamado en el art. 24-2 de la Constitución Española cuando en él se establece el derecho de todas las personas a un proceso con todas las garantías, dentro de las cuales se encuentra ineludiblemente el de la posibilidad de 
contradicción que acogiéndose al aforismo romano de "audiatur in altera pars" se ha venido manteniendo, como principio general del derecho, a través de todas las sociedades y tiempos.

Pero, ahora bien, como dice Gimeno Sendra, el principio de contradicción necesita ser completado con el de igualdad de armas (die waffengleiheit), porque no es suficiente que exista contradicción en el proceso, sino que, para que esta sea efectiva, se hace necesario que ambas partes tengan las mismas posibilidades y cargas de ataque y defensa, de alegación, de prueba e impugnación.

El mencionado principio de igualdad de armas que complementa al de contradicción, aparece proclamado en el art. 14 de la Constitución Española, que establece el principio constitucional de igualdad, y este principio ha de ser aplicado indiscriminadamente en todas y cada una de las fases e instancias del proceso.

Ahora bien, todo lo anterior no significa que existan procesos que por ausencia relativa del principio procesal de contradicción, puedan ser tachados de nulos e inconstitucionales. Se puede poner como ejemplos, no agotadores de la cuestión los siguientes:

a) Los procedimientos sumarios ejecutivos.

b) El de ejecución Hipotecaria.

c) El de desahucio en cuanto afecta al subarriendo.

d) El de determinadas fianzas o cauciones que pudieran exigirse a algunas de las partes de un determinado proceso.

Todos ellos han sido reconocidos y amparados por el Tribunal Constitucional en concretas sentencias.

Dicho principio supone de una manera rotunda el derecho que tiene toda parte procesal a exponer todo aquello que convenga a la defensa de sus derechos e intereses legítimos, siendo, todo ello, parte el derecho a la tutela judicial efectiva que proclama el art. 24-1 de la Constitución Española. 
El principio procesal civil de defensa, destacado y reconocido por la sentencia del Tribunal Constitucional 222-1.988 presenta tres aspectos fundamentales como con anterioridad había indicado de una manera colateral la sentencia del mismo Tribunal, los cuales son:

a) El emplazamiento personal de la parte en el proceso.

b) El derecho a utilizar los medios de prueba en la propia defensa.

c) El derecho a obtener el beneficio de justicia gratuita en determinadas ocasiones.

El primer aspecto se basa en el principio elemental de que nadie puede ser condenado (se habla desde un punto de vista del derecho privado) sin ser oído, y para ello es preciso que se le haga saber que se va a iniciar o se ha iniciado un proceso contra él, o por lo menos, que se va a ver implicado en el mismo.

El segundo aspecto supone el derecho a utilizar los medios de prueba pertinentes para la propia defensa, ejercitables en cualquier tipo de proceso, y que las pruebas pertinentes sean admitidas y practicadas por el Juez o Tribunal, sin desconocerlas u obstaculizarlas, e incluso prefiriéndose el exceso en la admisión, a una postura restrictiva.

El tercer aspecto parte de la base de que la realización efectiva del principio de defensa en nuestro ordenamiento jurídico se lleva a efecto mediante la asistencia técnica del Abogado, y así el art. 24-2 de la Constitución Española lo exige y el art. 238-3 de la Ley Orgánica del Poder Judicial establece la nulidad de todo acto procesal que no se atenga al antedicho principio.

Ahora bien, cuando el ciudadano carece de medios para ser asistido por un abogado, los poderes públicos tienen la obligación de proporcionarle tal asistencia.

Lo dicho anteriormente aparece matizado en las sentencias de 9-X-79 y 25-IV-83 del Tribunal Europeo de Derechos Humanos, cuando dicen que la negación del derecho a la asistencia letrada gratuita en proceso que permite la comparecencia personal, sólo constituirá vulneración constitucional si la autodefensa ejercitada por aquel a quien se niega el derecho, se manifiesta incapaz de compensar la ausencia de 
Abogado que lo defienda y, por lo tanto, de contribuir satisfactoriamente al examen de las cuestiones jurídicas suscitadas en el proceso.

Ya para concluir la cuestión, es preciso recalcar paradigmáticamente que todos estos principios esenciales para la realización correcta de un proceso civil, son derivaciones del derecho fundamental a obtener la tutela judicial efectiva, tutela esta que constituye un derecho fundamental de la persona, cuando la misma se adentra en un área judicial, y que sin dicha tutela nunca se podrá hablar de un Estado social y democrático de Derecho.

Muchas gracias. 